\title{
Validation of Computationally Predicted Substrates for Laccase
}

\author{
Reena $^{1}$, Purnima Dhall ${ }^{1}$, Rita Kumar ${ }^{1}$ and Anil Kumar ${ }^{2 *}$ \\ ${ }^{I}$ Environmental Biotech Division; Institute of Genomics and Integrative Biology; Delhi - India. ${ }^{2}$ National Institute \\ of Immunology; New Delhi - India
}

\begin{abstract}
Present study reports the validation (oxidation) of computationally predicted oxidation of xenobiotic contaminants by commercially available pure laccase from Trametes versicolor. Selected contaminants were predicted as potential targets for laccase oxidation by using in-silico docking tool. The oxidation by laccase was measured by change in absorbance at specific $\lambda$ max of each compound. Sinapic acid and tyrosine were taken as positive and negative controls, respectively. Oxidation was observed in m-chlorophenol, 2,4 di-chlorophenol, 2,4,6 trichlorophenol, captan, atrazine and thiodicarb, except malathion, which showed no activity. It could be speculated that the predicted substrates showing oxidation shared homology at structural and chemical level with positive control compounds. In case of malathion, structural non-homology with sinapic acid could be attributed to its inactivity towards laccase that required further structural analysis. Thus, a remediation tool proposing an advanced remediation approach combining the application of theoretical in-silico method and subsequent experimental validation using pure laccase could be proposed. As number and type of xenobiotics increase, the unfeasibility to screen them experimentally for bioremediation also rise. This approach would be useful to reduce the time and cost required in other screening methods.
\end{abstract}

Key words: biodegradation, In silico screening, laccase, xenobiotics

\section{INTRODUCTION}

Industrial and agriculture practices results the release high level of xenobiotic compounds, such as polycyclic aromatic hydrocarbon (PAH), pentachlorophenol (PCP), polychlorinated biphenyls (PCB), DDT, pesticides, benzene, toluene, ethylbenzene, xylene and TNT in the environment (Riva 2006). These are highly toxic and persistent in nature, many of them exert mutagenic and carcinogenic effects on living systems (Samanta 2002; Alcalde et al. 2006). Hence, in view of public health, it becomes necessary to put serious efforts in order to remove them from the environment. Available physico- chemical or mechanical methods require huge chemicals and energy input that enhance process cost and burden on environment. Biodegradation, biostimulation and biotransformation are cost feasible environmental friendly strategies that have wide application in xenobiotics remediation (Rao et al. 2010).

Laccase, a blue copper oxidoreductase [EC:1.10.3.2] is widely used enzyme in bioremediation of xenobiotics (Jurado et al. 2011). Laccases have ability to oxidize both phenolic and non-phenolic lignin related compounds and highly recalcitrant environmental pollutants, which make them attractive and useful tool to serve in biotechnological processes, detoxification of

*Author for correspondence: anilk@nii.ac.in 
effluents from pulp and paper industry, textile industry and petrochemical industries (Pinheiro et al. 2004). Laccases have been used as tool for medical diagnostics, as cleaning agents for water purification, as catalysts for the manufacturing of anti-cancer drug and even as ingredients in cosmetics (Shraddha et al. 2011). Their broad substrate specificity makes them able to remove xenobiotic substances (Couto et al. 2006). Since laccases catalyze a wide range of enzymatic reactions, they have also gained considerable biotechnological importance (Durán and Esposito 2000; Leonowicz et al. 2001; Mayer and Staples 2002). They are used as carrier to remove the plant cell wall inhibitors from sugarcane bagasse hydrolysate to obtain desired ethanol yields via microbial reactions (Chandel et al. 2007). A number of biosensors containing laccase have been developed for immunoassays, and for determination of glucose, aromatic amines and phenolic compounds (Kunamneni 2008).

White-rot fungi are main laccase producing organisms in soil, which enable them to grow on various toxic compounds and degrade the pollutants in the soil (Jurado et al. 2011). Enzymes are preferred over the microorganism to work as remediating agent because they can work in harsh environment. Enzyme mediated degradation of pesticides has two advantages; firstly, the degradation reaction proceeds under relatively mild reaction condition and secondly, the reaction rate is faster than that by microorganisms (Couto et al. 2009).

The list of xenobiotics is huge and growing. It is not appropriate to experimentally screen them all to find candidates for which bioremediation can be carried out. Therefore, studies have been carried out to develop in silico methods to know the possibility of degradation of a xenobiotic compound by an enzyme like laccase. Various bioinformatics methods have been developed to determine the kinetic constant, redox potential of laccase mediated reactions, etc. Some have provided both structural and experimentally determined potentials of laccase for substrate degradation. These theoretical methods may be useful in facilitating in silico prediction of substrates for laccase (Librando et al. 2013). Xenobiotic compounds of present study have previously been predicted as substrates for laccase by docking (Suresh et al. 2008). The aim of present study was to validate the prediction strategy applied to screen xenobiotics.
Degradation study has been performed for selected compounds to find out whether they respond similarly towards laccase as in the lab. The approach can be useful to develop better remediation strategy.

\section{MATERIALS AND METHODS}

\section{Materials}

All the chemicals (sinapic acid, L-tyrosine, Dtyrosine, m-chlorophenol, di-chlorophenol, trichlorophenol) and pesticides (thiodicarb, malathion, atrazine, captan) were purchased from Sigma-Aldrich (St. Louis, MO, USA). Purified laccase (source organism Trametes versicolor) was purchased from Sigma-Aldrich containing 26 U/mg. Laccase-pollutant docking was carried out using GOLD vs.3.0 and docking procedure was performed using both chemscore and goldscore function. The predicted substrates were experimentally evaluated.

\section{Oxidation of xenobiotic compounds by laccase}

Enzyme assay of laccase was performed in cuvette in Brittson and Robinson (BR) buffer ( $\mathrm{pH} 4.5$ ). Enzyme stock was prepared in 0.1M BR buffer and stored at $4^{\circ} \mathrm{C}$. The $0.1 \mathrm{mM}$ BR buffer was prepared by mixing equal volumes of boric acid $(0.1 \mathrm{M})$, orthophosphoric acid $(0.1 \mathrm{M})$ and acetic acid $(0.1 \mathrm{M}) . \mathrm{pH}$ was adjusted to 4.5 by using $1 \mathrm{~N}$ $\mathrm{NaOH}$ solution (Xu 1996). Thiodicarb, malathion and atrazine were dissolved in $90 \%$ methanol. $\mathrm{m}$ chlorophenol, di-chlorophenol and trichlorophenol were dissolved in methanol (50\%), while captan was dissolved in acetone $(90 \%)$ and tyrosine in water with $\mathrm{HCl}(0.1 \mathrm{M})$. All the buffers and solutions were prepared by using double distilled deionized water. Final reaction mixture contained substrate $(0.1 \mathrm{mM})$, enzyme $(0.5 \mathrm{U})$ and BR buffer ( $\mathrm{pH} 4.5$ ) in $2.0 \mathrm{~mL}$ reaction volume. After the addition of enzyme, absorbance was measured at 0,15 and 30 min time interval on spectrophotometer (UV-1700 Pharmaspec, SHIMADZU Japan) (Palmieri et al. 1997). The absorbance was measured at $\lambda$ max of each compound (sinapic acid-315 nm, L-tyrosine-280 $\mathrm{nm}$, D-tyrosine-280 nm, captan-263 nm, thiodicarb-235 nm, malathion-230 $\mathrm{nm}$ and atrazine-225 nm, m-chlorophenol-273 nm, dichlorophenol-28 4nm, tri-chlorophenol-285 nm). Control reactions for all the compounds were performed with inactive enzyme (boiled for 30 
min). Absorbance values represented the mean of three independent experiments. Sinapic acid and tyrosine were taken as positive and negative controls, respectively. All the experiments were performed in dark to avoid photo-oxidation of the substrates. Significance was measured for enzymatic activity by paired $t$ test.

\section{RESULTS AND DISCUSSION}

\section{Oxidation of predicted substrates by laccase}

Enzymatic activity of laccase with positive and negative control (sinapic acid and tyrosine, respectively) and with experimental xenobiotic compounds was examined by measuring the difference in absorbance (at $\lambda_{\text {Max }}$ ) at different time intervals. In positive control sample, the enzymatic activity of laccase with sinapic acid was observed as the decrease in absorbance with time, whereas in negative control sample (tyrosine), no enzymatic activity was observed. Chlorophenol compounds (m-chlorophenol, 2,4dicholorophenol, 2,4,6-trichlorophenol) and pesticides (thiodicarb, captan, and atrazine) were oxidized by laccase. One pesticide (malathion) from predicted compound was not oxidized by laccase. Docking score of predicted compounds indicated the efficiency of their degradation by laccase. Theoretically, higher the gold score, higher will be the oxidation of compounds by laccase. The score is based on the availability of some reaction promoting chemical features such as H-bonding energy, van-der waals energy, metal interaction, ligand torsion strain in enzyme and compound as well. The results of in silico prediction when compared with experimental results showed a similarity. Predicted substrates with high gold score were oxidized efficiently by laccase in comparison to those with low gold score. Although this was not applicable on all the substrates as some xenobiotics were very resistant molecules. The applicability of in silico tool to invent environmental remediation strategy could be a practical approach when combined with parallel pure enzyme based remediation. Figure 1 indicates the oxidation pattern of all the compounds. In case of m-chlorophenol, 2,4dichlorophenol and 2,4,6-trichlorophenol, higher oxidation by laccase were observed at 15 and 30 min time points as compared to $0 \mathrm{~min}$ value. In case of thidocarb, significantly higher $(p<0.05)$ oxidation was observed at 15 and 30 min than 0 min. For captan and atrazine, slight oxidation was observed at $15 \mathrm{~min}$ that became significantly higher at 30 min time point. Control experiments for each xenobiotic compound with heat inactivated laccase were carried out and no enzymatic activity was observed as indicated in Figure 2.



Figure 1 - Oxidation activity of laccase enzyme on various predicted substrates.

$\mathrm{N}^{\mathrm{o}} 1$ represents the positive control (sinapic acid), $\mathrm{N}^{\circ} 2$ and 3 are negative controls (tyrosine $\mathrm{D}$ and $\mathrm{L}$, respectively). $\mathrm{N}^{\mathrm{o}} 4,5,6,7,8,9$ and 10 are representing m-chlorophenol, 2,4dicholorophenol, 2,4,6-tricholorophenol, thiodicarb, malathion, captan and atrazine, respectively. Decrease in absorbance indicates the decreasing amount of substrate or higher enzymatic activity. Significant changes are denoted by $\$$, for $\mathrm{p}<0.001$, *, for $\mathrm{p}<0.01$ and \#, for $\mathrm{p}<0.05$. Error bars (I) indicate mean \pm SD from 3 independent experiments. 


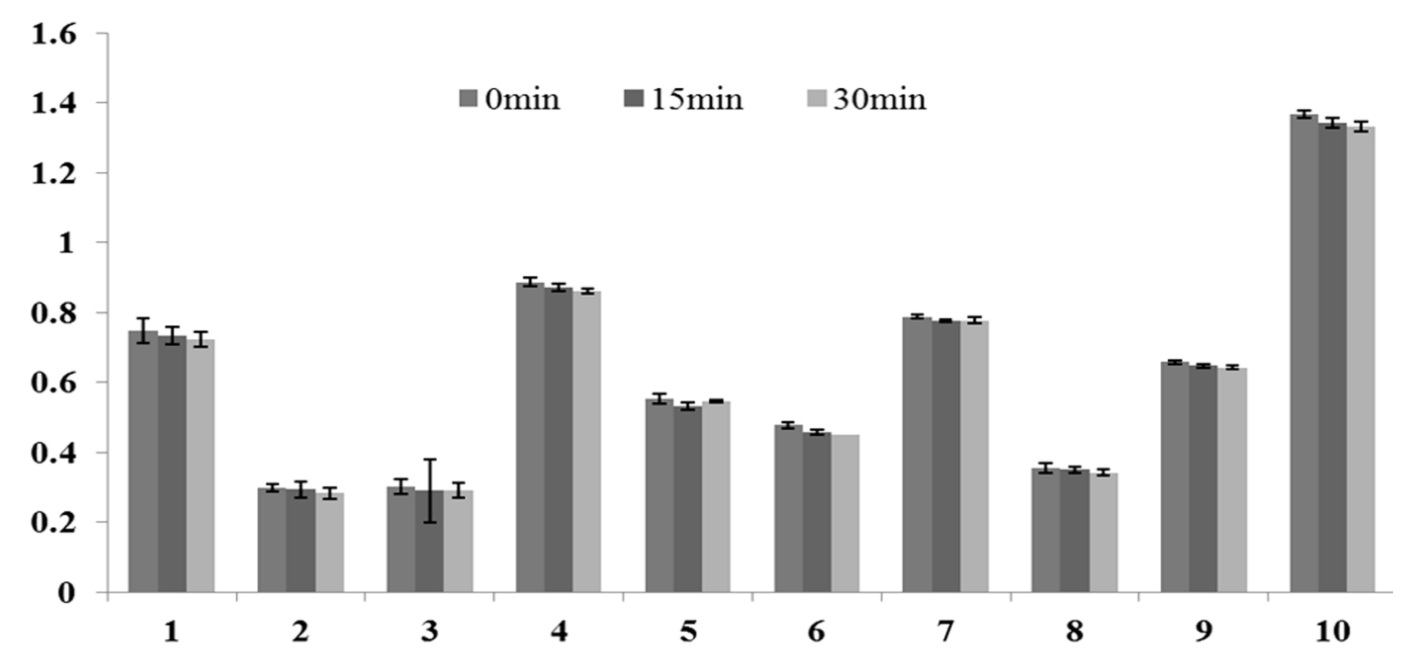

Figure 2- Oxidation activity of heat inactivated laccase enzyme on various predicted substrates. $\mathrm{N}^{0} 1$ represents the positive control (sinapic acid), $\mathrm{N}^{0} 2$ and 3 are negative controls (tyrosine D and L, respectively). $\mathrm{N}^{\mathrm{o}}$ 4, 5, 6, 7, 8, 9 and 10 are representing m-chlorophenol, 2,4-dicholorophenol, 2,4,6-tricholorophenol, thiodicarb, malathion, captan and atrazine, respectively. Enzyme activity was not observed for any substrate in all the samples as indicated by insignificant differences in absorbance at different time intervals. Error bars (I) indicate mean \pm SD from 3 independent experiments.

\section{Biodegradation promoting structures in xenobiotics}

Some structural features of xenobiotic compounds and their degradation by laccase have been investigated. Finding of these structural specificities would be important to know the exact mechanism of pesticide degradation by laccase. Structural influence of xenobiotic on the extent of their degradation by laccase was mentioned by Dominguez et al. (2007), particularly for PAH structures (anthracene, benzo pyrene, pbenzoquinone and phenanthrene), indicating the specificity of enzyme towards these substrates. Different laccases differ considerably in their catalytic preferences. Laccases can be grouped according to their preference for ortho-, meta- or para substituted phenols. Ortho-substituted compounds (guaiacol, o-phenylenediamine, caffeic acid, catechol, dihydroxyphenylalanine, protocatechuic acid, gallic acid and pyrogallol) were better substrates than para-substituted compounds (p-phenylenediamine, p-cresol, hydroquinone) and the lowest rates were obtained with meta-substituted compounds (mphenylenediamine, orcinol, resorcinol and phloroglucinol) with crude laccase (Baldrian et al. 2006). Prediction of substrate degradation by laccase, based on ionization potential has been done by various groups, but no obvious relationship has been established between the ionization potential and degradation percentage. Similar results were reported by other investigators (Pickard et al. 1999; Cho et al. 2002). In an in vivo study, (Farnet et al. 2009) showed that six laccase isoforms transformed anthracene and benzopyren. The PAH transformation were linked to the ionization potential (IP) of PAH. It was concluded that molecules with an IP $<7.55 \mathrm{eV}$ were degraded by laccase. The percentages of anthracene and benzopyrene transformation were higher when ABTS was used as mediator. The presence of redox mediators such as ABTS is required for the oxidation of complex substrates by laccase. Such mediators have been proven efficient system for the degradation of recalcitrant compounds (Piontek et al. 2002). Canas et al. (2010) discussed the application of lignin polymer related phenolic compounds as mediator that promoted the transformation of non-phenolic recalcitrant molecules by laccase. The study emphasized the use of lignocellulosic material to isolate natural, cheap, eco-friendly mediators for industrial uses of laccase to remediate the wastes generated through industrial processes. In another in silico study, the role of mediator molecule in the 
degradation of large dye molecule was predicted by docking, where the analysis of a dye molecule with enzyme showed that enzyme active site always could not accommodate dye molecule due to constructed nature of active site pocket and steric hindrance of the residues. The mediators, however, were relatively small in size, hence could be accommodated into active site pocket, which together led to the productive binding (Prasad et al. 2012). An interesting study by Reiss et al. (2013) on the oxidation of 91 natural and non-natural industrially relevant compounds by 11 laccasses and LMCOs of bacterial, fungal and plant origin was carried out to classify a newly identified bacterial multi copper enzyme as laccase. Even though the enzymes shared conserved active site residues, the substrate ranges of the individual laccase varied considerably. Such studies could lead designing of desired laccase by enzyme engineering of available 3D structures of laccases according to special requirement like in industrial waste remediation, cosmetic industry, refineries, etc. The main advantage in the approach is the broad substrate specificity of laccase, where enormous possibilities of innovation exist.

Among the predicted substrates, m-chlorophenol, 2,4-dichlorophenol and 2,4,6-tricholorophenol showed a higher degree of structural homology with sinapic acid. Significant decrease in the absorbance of these compounds at $15 \mathrm{~min}$ and 30 min time intervals reflected their relatively faster extinction and thereby indicating higher enzymatic activity. Thus, it could be speculated that higher enzymatic activity was attributed to their structural homology to the known substrates such as sinapic acid. They all have aromatic benzene ring and reactive phenol group. However, contradictory results were also obtained in case of thiodicarb and malathione. Despite of higher Gold score (table 1), malathion was not oxidized by laccase, whereas thiodicarb exhibited slow oxidation. The reason of this anomaly, however, lied in the very complex prediction parameters and stringencies of docking calculations (Sousa et al. 2006). The aromatic rings, hydroxyl groups and less ring substitution or chlorination are some biodegradation promoting structures whose presence in xenobiotic compound can lead to their biodegradation by laccase. Librando et al. (2013) have compiled an interesting review on in silico methods and their application in bioremediation of pollutants. It was observed that the results of computer simulations used to study laccase agreed well with corresponding experimental data, indicating a high degree of reliability. Delavari et al. (2013) performed docking to characterize the laccase binding pocket of different species in order to establish their common pharmacophoric characteristics. A common $\mathrm{km}$ value was also rationalised for a specific substrate oxidised by different laccases. The study was useful in order to understand the oxidation mechanism of laccase for ABTS mediator.

Table 1 - GOLD average fitness score of known and newly predicted substrates for laccase.

\begin{tabular}{lc}
\hline Name & GOLD average fitness score \\
\hline Sinapic Acid & 37.32 \\
L-Tyrosine & 19.07 \\
D-tyrosine & 20.82 \\
m-Chlorophenol & 30.25 \\
2,4-Dichlorophenol & 30.22 \\
2,4,6- Trichlorophenol & 32.17 \\
Captan $_{\mathrm{a}}$ & 44.23 \\
Thiodicarb $_{\mathrm{a}}$ & 59.01 \\
Malathion $_{\mathrm{a}}$ & 57.29 \\
Atrazine $_{\mathrm{a}}$ & 44.24 \\
\hline
\end{tabular}

\section{Microbial degradation of pesticides}

Microbes have the ability to degrade the pesticides from the environment. This specialty is contributed by different types of enzymes present in microbes. Laccase is one of them, which has broad substrate specificity, hence is able to degrade wide range of pollutants (Kosehorreck et al. 2009). The simplest case to understand the mechanistic point of reaction catalysed by laccase, is the one in which the substrates are oxidized to corresponding radicals by direct interaction with the copper cluster. This reaction gives rise to the radicals that can spontaneously rearrange, leading to fission of $\mathrm{C}-\mathrm{C}$ or $\mathrm{C}-\mathrm{O}$ bonds of the alkyl side chains, or to cleavage of aromatic rings. The substrates of interest cannot be oxidized directly by laccases, either because they are too large to penetrate into the enzyme active site or because they have a particularly high redox potential. By mimicking nature, it is possible to overcome this limitation with the addition of so-called 'chemical mediators', which are suitable compounds that act as intermediate substrates for the laccase, whose oxidized radical forms are able to interact with the bulky or high redo potential substrate targets (Kunamneni et al. 2008). The potential of 
microbial laccase (Cerrena unicolor) to oxidize herbicide, simazine via oxidative coupling reactions has been explored by Sannino et al. (1999). Although Filazzola et al.(1999) showed that simazine behaved as an inhibitor of laccasemediated-catechol transformation and its degradation occurred as a consequence of the production of the oxidases (lignin peroxidase, manganese peroxidase, laccase) required for the depolymerization of lignin. Although no correlation found between atrazine degradation and laccase activity was studied by Vasilchenko et al. (2002). They studied the decomposition of atrazine by laccase positive and laccase negative clones of Mycelia sterilia INB12-26. In another study, $T$. versicolor proved as a strong candidate for bioremediation of atrazine in the soil with low moisture and organic contents (Bastos and Magan 2009). The degradation of organophosphorus compounds by the purified fungal laccase using small molecular weight redox mediator was studied by Leroy et al (2010). LMS were very efficient to promote $\mathrm{OP}$ degradation by laccase. Here the importance of the OP nitrogen atom at beta-position and of its substituents was mentioned, though the intimate mechanism of laccase catalysed degradation was not yet known. LMS has been tested in the decolorization of a recalcitrant azo dye Reactive Black 5 (RB5). Both acetosyringone and syringaldehyde demonstrated high mediating ability for RB5 decolorization (Wang et al. 2011).

\section{CONCLUSION}

Present study showed the ability of combined approach using laccase as remediation tool for the oxidation of xenobiotic compounds from the environment. Broad substrate specificity of laccase favored its wide spread application in pulp and paper, textile and food processing industry. Predicted compounds were used for the validation of the prediction approach by carrying out their oxidation/degradation. All the compounds were oxidized by laccase, except one. Differences in the structure of xenobiotic compounds were responsible for their extent of oxidation, which could be improved by adding laccase mediator. The approach could be time saving and environmental friendly, as computer based screening and prediction of xenobiotics eliminated the chemical input demanded in traditional methods.

\section{ACKNOWLEDGMENT}

Experimental work has been carried out at Institute of Genomics and Integrative Biology, New Delhi, India. The authors acknowledge the financial help provided by the Department of Biotechnology, Government of India.

\section{REFERENCES}

Alcalde M, Ferrer M, Plou FJ, Ballesteres A. Environmental Biocatalysis: From remediation with enzymes to novel green processes. Trends Biotechnol. 2006; 24: 281-287.

Baldrain P. Fungal laccases- occurance and properties. FEMS Microbiol Rev. 2006;30(2):215-242.

Bastos AC, Magan N. Trametes versicolor: potential for atrazine bioremediation in calcarious clay soil, under low water availability conditions. Int Biodeter Biodeg. 2009; 63: 389-394.

Canas AI, Camarero S. Laccases and their natural mediators: biotechnological tools for sustainable ecofriendly processes. Biotechnol Adv. 2010; 28(6): 694705.

Cho SJ, Park SJ, Lim JS, Rhee YH, Shin KS. Oxidation of polycyclic aromatic hydrocarbons by laccase of Coriolus hirsutus. Biotechnol Lett. 2002; 24: 13371340.

Couto SR, Herrera JLT. Pesticide degradation by laccase. In: Kanzantzakis C M. Progress in pesticide research. New York: Nova Science Publisher; 2009. 475-490.

Couto SR. Herrera JLT. Industrial and biotechnological applications of laccases: A review. Biotechnol Adv. 2006; 24: 500-513.

Chandel AK, Kapoor RK, Singh A, Kuhad RC. Detoxification of sugarcane bagasse hydrolysate improves ethanol production by Candida shehatae NCIM 3501. Bioresource Technol. 2007; 98: 19471950.

Delavari A, Perez JJ. Computational study of substrates and mediators features of lacasses. J Biomol Stru Dyna. 2013; 31:1,136-137.

Dominguez A, Gomez J, Lorenzo M, Sanroman A. Enhanced production of laccase activity by Trametes versicolor immobilized into alginate beads by the addition of different inducers. World J Microb Biot. 2007; 23: 367-373.

Durán N, Esposito E. Potential applications of oxidative enzymes and phenoloxidase-like compounds in wastewater and soil treatment: a review. Appl Catal B: Environ. 2000; 28: 83-99. 
Farnet AM, Gil G, Ruaudel F, Chevremont AC, Ferre E. Polycyclic aromatic hydrocarbon transformation with laccases of a white-rot fungus isolated from Mediterranean schlerophyllous litter. Geoderma. 2009; 149: 267-271.

Filazzola MT, Sannino F, Rao MA, Gianfreda L. Effect of various pollutants and soil-like constituents on laccase from Cerrena unicolor. J Environ Qual. 1999; 28: 1929-1938.

Jurado M, Martinez AT, Martinez MJ. Application of white-rot fungi in transformation, detoxification, or revalorization of agriculture wastes: Role of laccase in the process. In: Young MM. $2^{\text {nd }}$ edition. Comprehensive Biotechnology. Elsevier Publication. 2011; 6: 595-603.

Kosehorreck K, Schimd RD, Urlacher VB. Improving the functional expression of a Bacillus licheniformis laccase by reduction and site directed mutagenesis. BMC Biotechnol. 2009; 9: 1-10.

Kunamneni A, Plou FJ, Ballesteros A, Alcalde M. Laccases and their applications: a patent review. Recent Pat Biotechnol. 2008; 2(1): 10-24.

Leroy TM, Jolivalt C, Froment MT, Brasme B, Lefebvre B, Daveloose D, et al. Application of laccase-mediator system (LMS) for the degradation of organophosphorus compounds. Chem Biol Interact. 2010; 187:393(6): 1-3.

Leonowicz A, Cho NS, Luterek J, Wilkolazka A, Wojtaswasilewska M, Matuszewska A, et al. Fungal laccase: properties and activity on lignin. J Basic Microbiol. 2001; 41: 185-227.

Librando V, Pappalardo M. In silico bioremediation of polycyclic aromatic hydrocarbon: A frontier in environmental chemistry. J Mol Graph Model. 2013; 44: 1-8.

Mayer AM, Staples RC. Laccase: New functions for an old enzyme. Phytochemistry. 2002; 60: 551-565.

Palmieri G, Giardina P, Bianco C, Scaloni A, Capasso A, Sannia G. A novel white laccase from Pleurotus ostreatus. J Biol Chem. 1997; 272: 31301-31307.

Pickard MA, Roman R, Tinoco R, Vazquez-Duhalt R. Polycyclic aromatic hydrocarbon metabolism by white rot fungi and oxidation by Coriolopsis gallica UAMH 8260 laccase. Appl Environ Microbiol. 1999; 65: 3805-3809.

Pinheiro HM,Touraud E, Thomas O. Aromatic amines from azo dye reduction: status review with emphasis on direct UV spectrophotometric detection in textile industry wastewaters. Dyes and pigments. 2004; 61: 121-139.

Piontek K, Antorinis M, Choinowski T. Crystal structure of a Laccase from the fungus Trametes versicolor at $9.10 \mathrm{~A}^{\circ}$ Resolution containing a full complement of coppers. J Biol Chem. 2002; 277(40):37663-37669.
Prasad NK, Vindal V, Narayana SL, Ramakrishna V, Kunal SP, Srinivas M. In silico analysis of Pycnoporus cinnabarinus laccase active site with toxic industrial dyes. J Mol Model. 2012;18(5). 20132019.

Rao MA, Scelza R, Scotti R, Gianfreda L. Role of enzymes in the remediation of polluted environments. J Soil Sci Plant Nutr. 2010; 10 (3): 333-353.

Riva S. Laccase: Blue enzyme for green chemistry. Trends Biotechnol. 2006; 24: 219-226.

Reiss R, Ihssen J, Richter M, Eichhorn E, Schilling B, Meyer TL. Laccase versus Laccase-Like MultiCopper Oxidase: A Comparative Study of Similar Enzymes with Diverse Substrate Spectra. PLOS One. 2013; 8(6):1-12.

Samanta SK. Polycyclic aromatic hydrocarbon: environmental pollution and bioremediation. Trend Biotechnol. 2002; 20: 243-248.

Sannino F, Filazzola MT, Violante A, Gianfreda L. Fate of herbicides as influenced by abiotic and biotic mechanisms. Chemosphere. 1999; 39: 333-341.

Shraddha, Shekher R, Sehgal S, Kamthania M, Kumar A. Laccase:Microbial Sources, Production, Purification, and Potential Biotechnological Applications. Enzyme Res. 2011; 217861: 1-11

Sousa SF, Fernandes PA, Ramos MJ. Protein-ligand docking: Current status and future challenges. Proteins. 2006; 65: 15-26.

Suresh PS, Kumar A, Kumar R, Singh VP. An in silico [correction of in silico] approach to bioremediation: laccase as a case study. J Mol Graph Model. 2008; 26: 845-849.

Vasilchenko LG, Khromonygina VV, Koroleva OV, Landesman EO, Gaponenko VV, Kovaleva TA, et al. Consumption of triazine herbicide atrazine by laccase-positive and laccase-negative strains of soil fungus Mycelia sterilia INBI 2-26. Appl Biochem Micro. 2002; 38(5):454-459.

Wang TN, Lu L, Li GF, Li J, Xu TF, Zhao M. Decolorization of the azo dye reactive black 5 using laccase mediator system. Afr J Biotechnol. 2011; 10(75):17186-11191

$\mathrm{Xu}$ F. Oxidation of phenols, anilines and benzenehiols by fungal laccases: correlation between activity and redox potentials as well as halides inhibition. Biochemistry. 1996; 35:7608-7614.

Received: August 01, 2013; Accepted: April 07, 2014. 